\title{
Sürekli Değişken Modele Dayalı Gözetimli Kuantum Makine Öğrenmesi ile Kişilerin Satın Alma Davranışlarının Tespitinin Simulasyonu
}

\author{
Ömer Eryılmaz ${ }^{1 *}$ İhsan Yılmaz ${ }^{2}$ \\ ${ }^{1}$ Çanakkale Onsekiz Mart Üniversitesi, Fen Bilimleri Enstitüsü,Bilgisayar Mühendisliği ABD \\ ${ }^{2}$ Çanakkale Onsekiz Mart Üniversitesi, Mühendislik Fakültesi,Bilgisayar Mühendisliği Bölümü \\ 04.03.2019 Geliş/Received, 27.05.2019 Kabul/Accepted
}

\section{Özet}

$\mathrm{Bu}$ çalışmada kişilerin satın alma davranışları sürekli-değişken modele dayalı gözetimli kuantum makine öğrenmesi ile incelenmiştir. Bu bağlamda, örnek veriler bulut ortamından alınmaktadır. Bu verilerin \%75'inin eğitim ve \%25'inin test verisi olarak, homojen bir şekilde ayrılması sağlanmıştır. Ayrılan test verisinin eğitim işleminde kullanılmamasına, öğrenme işleminin sağlıklı gerçekleştirilmesi için dikkat edilmiştir. Sonrasında bu verilerdeki bağımsız değişkenler arasındaki uyumun sağlanması için normalizasyon işlemi gerçekleştirilmiştir. Böylece öğrenme işlemi için hazır hale gelen veriler, sürekli değişken modele dayalı varyasyonel devre üzerinde gerçekleştirilen gözetimli kuantum makine öğrenme algoritmasında kullanılmıştır. Ayrıca bu veriler klasik destek vektör makine öğrenme algoritması ile de simüle edilmiştir. Hem kuantum hem de klasik makine öğrenme algoritmalarına ait çapraz tahmin matrisleri ve alıcı işletim karakteristiği (AİK) eğrileri elde edilmiştir. Son olarak veri kümesindeki test verisi haricinde örnek değerler girilerek, sonuçlar metinsel ve görsel olarak görüntülenmiştir. Elde edilen sonuçların karşılaştırılması sonucunda ise sürekli değişken modele dayalı kuantum makine öğrenmesinin daha duyarlı sonuç verdiği tespit edilmiştir. Algoritmalar ile ilgili kaynak kodlar Github’ta bulunmaktadır.

Anahtar Kelimeler: kuantum makine öğrenmesi, sürekli-değişken modelli kuantum hesaplama, kuantum bilgisayarlar.

\section{Simulation of Detection of Purchasing Behaviors of People Using Supervised Quantum Machine Learning Based on Continous-Variable Model}

\begin{abstract}
In this study, purchasing behavior of people is examined by supervised quantum machine learning based on continuous-variable model. In this context, sample data is taken from the cloud environment. These data is provided as homogenous separation as $75 \%$ training and $25 \%$ test data. Separated test data was not used in the training process, attention was paid to the healthy implementation of the learning process. Then, the normalization process was performed to ensure the consistency between the independent variables in this data. Thus, the data ready for the learning process are used in the supervised quantum machine learning algorithm performed on variational circuit based continuous variable model. In addition, these

*Sorumlu Yazar (Corresponding Author): Ömer Eryılmaz

(e-posta:omer-eryilmaz@hotmail.com)

Bu makale Ömer Eryılmaz'ın tez konusu kapsamında yazılmıştır.
\end{abstract}


data are simulated with the classical support vector machine learning algorithm. Confusion matrices and receiver operating characteristic (ROC) curves for both quantum and classical machine learning algorithms were obtained. Finally, by entering sample values except the test data in the data set, the results are displayed textually and visually. Based on the obtained results, it was determined that quantum machine learning based on continuous variable model is more sensitive. The source codes related to algorithms are found in Github.

Keywords: quantum machine learning, continuous-variable model, quantum computing.

\section{Giriş}

Yapay zekâ ve istatistiğin bir parçası olan makine öğrenme algoritmaları; görüntü ve konuşma tanıma, örüntü tanımlama veya strateji optimizasyonu gibi insan beynine doğal gelen görevler için büyük miktarda bilgi işlemektedir. Bu tarz bilgilerin depolanması ve işlenmesi elektronik sistemler için zorlu ve masraflı bir süreçtir. Bu tarz zorluklar neticesinde makine öğrenimi için yenilikçi yaklaşımlar bulmanın önemini artmaktadır. Son zamanlarda bilim dünyası ve önde gelen teknoloji şirketleri kuantum bilgisayarların potansiyellerini kullanarak klasik makine öğrenme algoritmalarının optimize edilmesini umut verici bir fikir olarak görmektedirler. $\mathrm{Bu}$ doğrultuda yapılan araştırmalar, kuantum algoritmaların klasik yöntemler üzerinde hızlanma sağlayabileceğini göstermiștir (Jordan, 2018). Bu gelișmeler doğrultusunda benzer tekniklerin makine öğrenimi alanında da uygulanarak olumlu sonuçlar alınabileceği ve bu gelişmeler neticesinde mevcut makine öğrenimi problemleri için yeni pratik çözümler sunulabileceği düşünülmektedir. Makine öğrenmesinde, eğitim aşamaları genellikle algoritmanın en maliyetli kısmı olarak görülmektedir. Öğrenme türü ve yöntemi ne olursa olsun, en uygun makine öğrenme algoritmaları asgari kaynaklarla çalışıp, minimum hata oranına sahip olmalıdır. En uygun çözümü sağlayan parametreleri ve başlangıç değerleri bulma problemine ya da algoritmanın karmaşıklık oranını düşüren planlar bulmaya odaklanmak bu işin en zorlanılan kısımları olarak görülmektedir (Schuld ve ark., 2014).

Kuantum bilgisayarlar, klasik bilgisayarların aksine 0 ve 1 'in ve aradaki diğer tüm olasılıkları değerlendirerek aynı anda işlem yaptığından hız ve veri depolama bakımından diğer bilgisayarlardan daha üstün özelliklere sahiptir. Kuantum makine öğrenmesinde, kuantum hesaplamanın verimliliğini kullanarak makine öğrenmesinin tipik problemlerini çözmek için kuantum algoritmaları geliştirilmektedir. Yakın gelecekte bu tür makinelerin, giderek artan miktardaki küresel bilgiyi işlemede yaygın olarak kullanılacağı öngörülmektedir (Schuld ve ark., 2014).

Gerçekte hesaplama terimleriyle eşdeğer fakat kavramsal olarak birbirinden farklı olan birkaç kuantum bilgisayar modeli bulunmaktadır. Bunlardan bir tanesi de kuantum bilgisayarların sürekli-değişken (SD) (continous variable) modelidir (Braunstein ve ark., 2005). Süreklideğişken modelinde, bilgi işlem birimi (information processing unit), sonsuz-boyutlu (infinite-dimensional) bosonik moddur. Sürekli-değişken modeli, bir dizi benzersiz özellik sunarken, kubit modelinin hesaplama gücünü de koruduğu belirtilmektedir (Nielsen ve ark., 2002). Ayrıca sürekli-değişken modeli, bosonik sistemleri (elektromanyetik alanlar, tuzaklanan atomlar, harmonik osilatörler, Bose-Einstein yoğuşması, fononlar ve optomekanik rezonatörler) ve sürekli kuantum operatörlerinin mevcut olduğu ortamları simüle etmek için de uygun görülmektedir (Killoran ve ark., 2018).

Bu öngörüler doğrultusunda bu çalışmada kuantum bilgisayarların üstün özelliklerinden yararlanılarak, makine öğrenmesinde karşılaşılan zorlukların ve maliyetin asgari miktarlara 
indirgenmesi amaçlanmaktadır. Bu amaç doğrultusunda örnek olarak, kişilerin satın alma davranışlarının kuantum makine öğrenmesi kullanılarak tespit edilmesine yönelik kuantum simülasyonu gerçekleştirilecektir. Sonrasında ise kuantum simülasyonda elde edilen sonuçlar ile klasik simülasyonda elde edilen sonuçlar karşılaştırılacaktır.

\section{Materyal ve Yöntem}

$\mathrm{Bu}$ çalışma, kuantum sürekli-değişken modelinde, varyasyonel devrenin gözetimli öğrenim algoritması üzerinde gerçekleştirilmektedir. Simülasyon ortamı için Strawberry Fields adında bir Python kütüphanesi kullanılmıştır (Killoran ve ark., 2018). Bu bağlamda kuantum makine öğrenmesi araç kutusu (QMLT) kullanılmıştır. QMLT, varyasyonel kuantum devrelerinin optimizasyon işlemini basitleştiren bir uygulama olarak tanımlanmaktadır (Killoran ve ark., 2018).

\subsection{Kişilerin Satın Alma Davranışlarının Kuantum Makine Öğrenmesi Kullanılarak Tespit Edilmesi}

Çalışma için yapılan örnekte, hem kuantum makine öğrenmesiyle hem de klasik makine öğrenmesiyle, iki boyutlu desen tanıma görevi için sınıflandırma işlemi gerçekleştirilmiş ve sonuçları karşılaştırılmıştır. Veri kümesi ise bulut ortamından güncel olarak alınıp, kullanılmaktadır. Bu veri kümesindeki örnekler, gerçeğe uygun bir şekilde tarafimızdan üretilmiştir ve "KullaniciID", "Cinsiyet", "Yas", "AlisverisSayisi", "SatinAldiMi" gibi özniteliklere sahip 211 adet örnekten (kişiye ait alışveriş bilgilerinden) oluşmaktadır. Buradaki "KullaniciID” özniteliği tam sayı (integer) türünde olup 0'dan yaklaşık olarak 2 milyara kadar değer alabilmektedir. "Cinsiyet" özniteliği karakter dizisi (string) türünde olup sadece "K" ve "E" karakterleri ile sınırlandırılmıştır. "Yas" özniteliği tam sayı (integer) türünde olup 0-120 aralığında "AlisverisSayisi" özniteliği tam sayı (integer) türünde olup 0-1000 aralığında değer alabilmektedir. Son olarak "SatinAldiMi" özniteliği ise mantıksal veri (boolean) türünde olup sadece 1 veya 0 değerlerini alabilmektedir. Ayrica bu özniteliklerden "KullaniciID” kişiye verilen benzersiz numarayı, "Cinsiyet", kişiye ait cinsiyet bilgisini, "Yas" kişiye ait yaş bilgisini, "AlisverisSayisi”" kişiye ait yıllık ortalama alışveriş sayısını, "SatinAldiMi” ise kişinin ilgili ürünü satın alıp almadığını temsil etmektedir.

Öncelikle iki boyutlu girdi verilerimizi ve bu girdilerin hedef olarak çıktıları ifade edecek özniteliklerin seçilmesi işlemi gerçekleştirilmiştir. Örneğimiz için bu özniteliklerin "Yas", "AlisverisSayisi" ve "SatinAldiMi" olarak belirlenmiştir. Geriye kalan, "KullaniciID" özniteliği herhangi belirleyici bir kriter olmadığından, "Cinsiyet" özniteliği ise örneğimizin 2-boyutlu veriler için gerçekleştirildiğinden öğrenme işlemi için kullanılmamışlardır.

Verikümesindeki örneklere ait "Alışveriş Sayısı" ve "Yaş" bilgileri, noktalar olarak Şekil 2.1.'de gösterilmektedir. Bu noktalardan siyah olanlar ilgili ürünün müşteri tarafindan satın alındığını, sarı olanlar ise ilgili ürünün müşteri tarafından satın alınmadığını temsil etmektedir. 


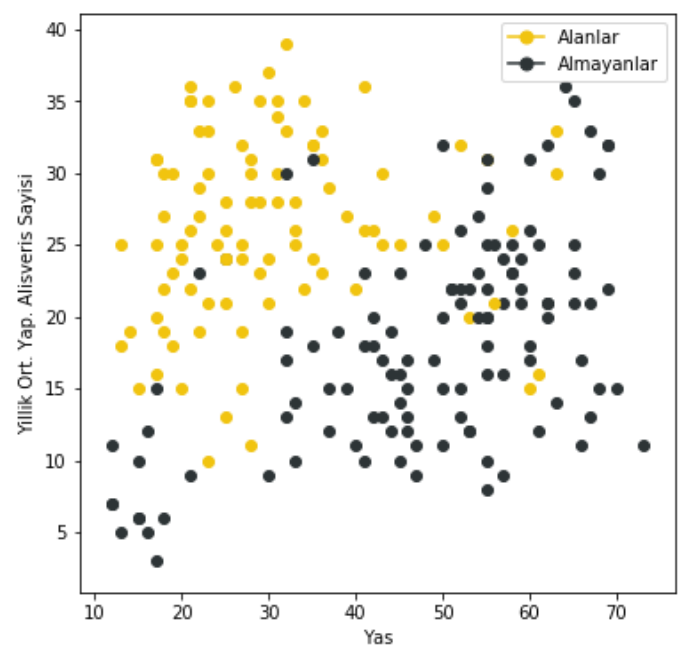

Şekil 2.1. Veri kümesindeki “Alışveriş Sayısı” ve "Yaş” dağılım grafiği.

Bu aşamadan sonra veriler $\% 75^{\prime}$ i eğitim, \%25'i test verisi olmak üzere ikiye ayırılmıştır.

Verileri, "Eğitim" ve "Test" verisi olarak ikiye ayrıldıktan sonraki durumu Şekil 2.2.'de gösterilmektedir. İlgili şekilde mavi noktalar "Eğitim", kırmızı noktalar ise "Test" verilerini temsil etmektedirler. Öğrenme işleminin sağlıklı gerçekleştirilebilmesi için "Test”" verisinin tüm veri kümesinden homojen olarak seçilmesine dikkat edilmektedir. "Alışveriş Sayısı" ve "Yaş" bağımsız değişkenlerinin aynı birimde olmadıkları görülmektedir. Öğrenme işleminde olumsuzluklara yol açmaması için bağımsız değişkenlere normalizasyon işlemi uygulanmştır.

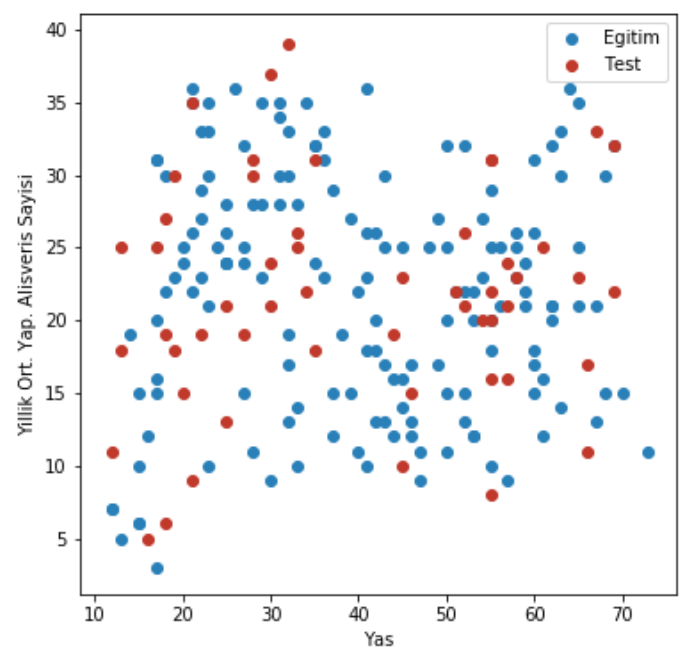

Şekil 2.2. Verilerin "Eğitim" ve "Test" verisi olarak ayrılması

Verilerin normalizasyon işleminden sonraki aldığı değerler Şekil 2.3'de görülmektedir. Normalizasyon işlemi, MinMaxScaler metoduyla gerçekleştirilmiştir. MinMaxScaler metodu öznitelikleri istenilen aralığa ölçeklendirmeyi sağlamaktadır. Böylece iki bağımsız değişkendeki değerlerin 0 ve 1 dâhil olmak üzere, o aralıktaki değerlerde olması sağlanmıştır. 


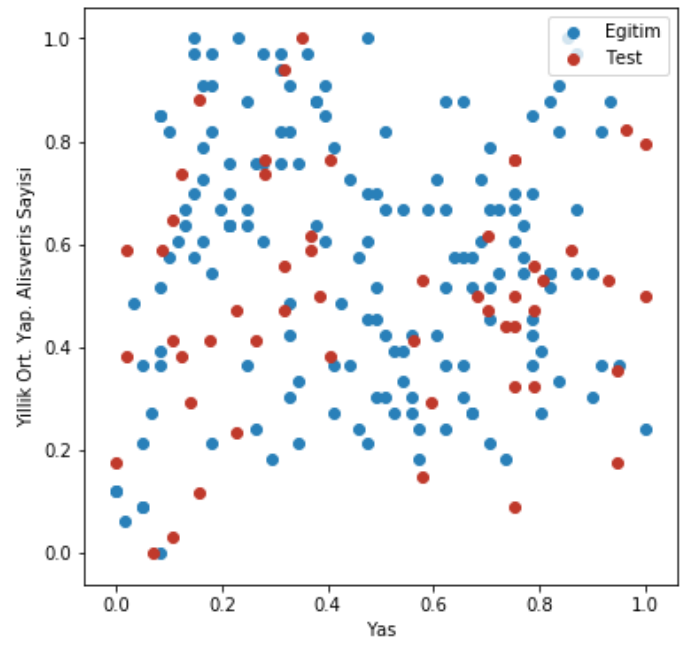

Şekil 2.3. Verilerin normalizasyon uygulanmış hali

Bundan sonraki aşamada kuantum makine öğrenmesi işlemleri gerçekleştirilmektedir. İki sınıf arasında, ikili (binary) iki boyutlu desen tanıma görevi için varyasyonel devre eğitilmektedir. $\mathrm{Bu}$ öğrenme işleminde ilk olarak Strawberry Fields kütüphanesi, yerdeğiştirme kapısı, 1şın-ayırıcı kapısı, öğrenici ve yardımcı kütüphaneler koda dahil edilmektedir. Devre fonksiyonu ve devrenin ilgili parametreleri tanımlandıktan sonra öğrenme işlemine geçilmektedir (Şekil 2.4).

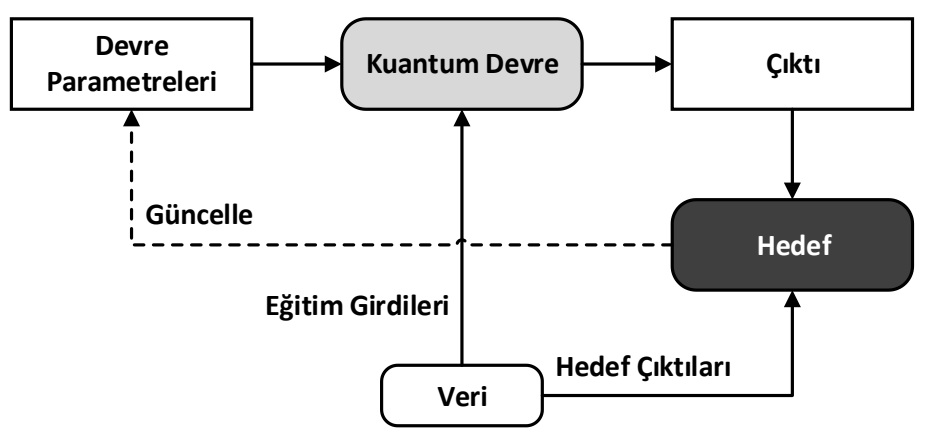

Şekil 2.4. Varyasyonel devre üzerinde gerçekleştirilen gözetimli öğrenme algoritmasının çalışma diyagramı (Schuld, 2018)

Varyasyonel devre üzerinde gerçekleştirilen gözetimli öğrenmede, desen tanıma görevi için varyasyonel devre eğitilmektedir. Bu işlem için ilgili kodda belirtilen fonksiyon aracılığıyla girdi verileri devreye iletilir. Veriler, bir grup girdi içerdiğinden başka bir fonksiyon yardmıyla da kuantum devresi tek girdili vektörler için çalışmaya uygun hale getirilmektedir. Böylece kuantum devre, tek seferde sadece bir girdiyle beslenebilecek hale getirilmiş olur (Izaac, 2018a).

Schuld ve ark. (2018) tarafından önerilmiş devre-merkezli kuantum sınıflandırıcısının devresi ve devrenin işleyiş şeması Şekil 2.5 'de gösterilmektedir. Devrede bulunan $S_{x}$, x girdilerini kuantum sisteminin genliği içinde kodlayan durum hazırlama devresini, $U_{\theta}$ ise işlemlerin gerçekleştirildiği birimsel kapılarla oluşturulan model devresini temsil etmektedir. $f(x, \theta)=y$ modelindeki çıkarım işlemi bir kuantum cihazı olan kuantum işlemci ünitesi (QPU) tarafından gerçekleştirilmektedir (Izaac, 2018a). 


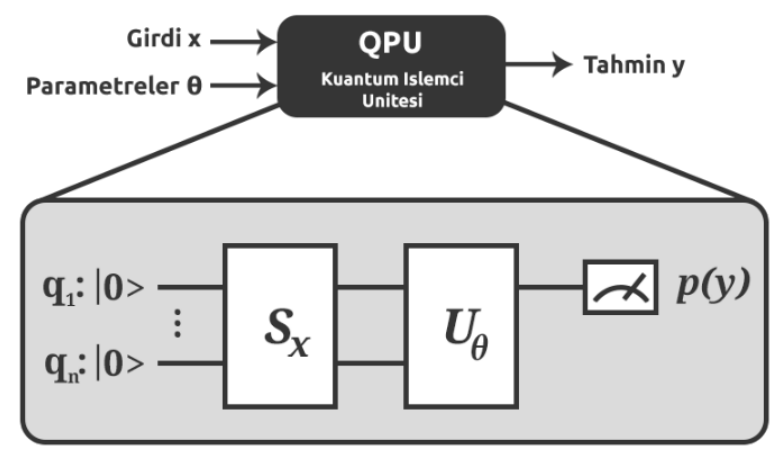

Şekil 2.5. Devre-merkezli kuantum sınıflandırıcı (Schuld et al., 2018)

$U_{\theta}$ model devresinin, yer değiştirme (displacement) ve ışın ayırıcı (beamsplitter) kapılarından oluştuğu Şekil 2.6.'da gösterilmektedir.

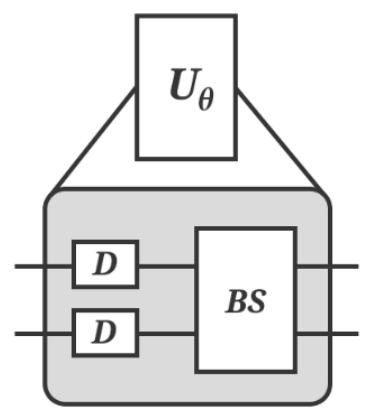

Şekil 2.6. Model devresini oluşturan birimsel kapılar

Çalışmada kullanılan Strawberry Fields kütüphanesi sayesinde QPU'nun simülasyonunda makine öğrenme işlemi gerçekleştirilmiştir. $\mathrm{Bu}$ simülasyon ortamında ProjectQ ile modellenen ve SD ayarlamalarında özelleştirilmiş Blackbird programlama dili kullanılmıştır.

İlk olarak x klasik verileri $S_{x}$ (durum hazırlama devresi) fonksiyonu ile n kübit kuantum durumlarına kodlanır. Burada girdi $x \in \mathbb{R}^{N}$ verileri $2^{n}$-boyutlu $\varphi(x)$ genlik vektörü olarak başlangıç kuantum durumuna $|\varphi(x)\rangle$ haritalanmaktadır. Elde edilen kuantum durumuna $U_{\theta}$ uygulanır. Sonucunda yeni bir durum olan $\left|\varphi^{\prime}\right\rangle$ durumu elde edilir.

$$
\left|\varphi^{\prime}\right\rangle=U_{\theta}|\varphi(x)\rangle
$$

Şekil 2.6'da görüldüğü üzere $|\varphi(x)\rangle$ durumuna etki eden ilk kapılar/operatörler aşağıdaki şekilde ifade edilen yer değiştirme (displacement) kapılarıdır.

$$
D_{i}(\alpha)=\exp \left(\alpha \hat{a}_{i}^{\dagger}-\alpha^{*} \hat{a}_{i}\right)
$$

Yukarıdaki formülde belirtilen $\alpha$ karmaşık genliği temsil etmektedir.

$$
\alpha=(q+i p) / 2
$$

Ayrica;

$$
D(\alpha)=\exp \left(\alpha \hat{a}^{\dagger}-\alpha^{*} \hat{a}\right)=\exp \left(r\left(e^{i \varphi} \hat{a}^{\dagger}-e^{-i \varphi} \hat{a}\right)\right)
$$


$D^{\dagger}(\alpha) \hat{a} D(\alpha)=\hat{a}+a$ I burada $r \geq 0$ ve $\varphi=[0,2 \pi)$ olmak üzere $\alpha=r e^{i \varphi}$ 'dir.

Yer değiştirme kapısı vakum durumuna (5) eşitliğindeki gibi etki ederek onun durumunu değiştirmektedir. Bu etki sonucunda eşitlik (4)'deki tutarlı durum elde edilmektedir (Izaac, 2018b).

$$
|\alpha\rangle=\mathrm{D}(\alpha)|0\rangle
$$

İlgili kumod'lara etki eden ikinci kapı da aşağıda ifade edilen ışın ayırıcı (beamsplitter) kapisidır. (Izaac, 2018b).

$$
\operatorname{BS}_{\mathrm{ij}}(\theta, \phi)=\exp \left(\theta\left(\mathrm{e}^{\mathrm{i} \phi} \hat{\mathrm{a}}_{\mathrm{i}}^{\dagger} \hat{\mathrm{a}}_{\mathrm{j}}-\mathrm{e}^{-\mathrm{i} \phi} \hat{\mathrm{a}}_{\mathrm{i}} \hat{\mathrm{a}}_{\mathrm{j}}^{\dagger}\right)\right)
$$

Eşitlik (6)'da $\hat{a}_{i}$ imha, $\hat{a}_{j}$ oluştuma operatörlerini, $\theta$ ise 1 şın ayırıcının geçirgenliğini temsil etmektedir $\left(T=\cos ^{2} \theta \in[0,1]\right)$. Işın ayırıcı, $T=1 / 2$ olduğunda dengeli olarak adlandırılmaktadır (Izaac, 2018b).

Son olarak ölçme işlemi yapılarak, fock durumu olarak tanımlanmış olan modelin çıktısı elde edilmektedir.

Kuantum makine öğrenmesi kaba-kodu Şekil 2.7'de gösterilmektedir. Burada kuantum makine öğrenmesi işlem adımları basit bir şekilde listelenmeye çalışılmıştır. 


\section{Başlat}

2. Girdiler: $\quad X$ örnek özellik vektörlerinin listesi

$\boldsymbol{Y}$ çıktıların (etiketlerin) listesi

steps algoritmanın tekrar sayısı

params eğitilecek varyasyonel devre ile ilgili parametreler

batch_size Her parametre güncellemesi için kullanılan eğitim girdilerinin miktarı

\section{Varyasyonel Devre Eğitimi:}

4. Döngü: steps sayısı kadar

5.

Varyasyonel Devre Fonksiyonu(X, params):

6.

\section{Kuantum Derleryici Motorunu Oluştur}

7.

Döngü: $X$ örnek listesi oluşturan $x$ örneklerinin sayıs1 kadar

8.

$x$ örneklerini teker teker kumod'lara ata

9. kumodlar üzerinde ölçme işlemi gerçekleştir

10. normalizasyon işlemi gerçekleştir

11. outp $=$ normalizasyon sonucu

12. Çıktı: circuit_output yani tüm $\mathrm{x}$ örneklerinin normalizasyon sonucu

13. Varyasyonel Devreyi Optimize Et: Devre çıktılarını ilgili etiketlerle ilişkilendirip model oluştur. Model başarısını hedef fonksiyonu ile sorgula ve sonuca göre params'1 güncelle.

\section{Bitir}

Şekil 2.7. Kuantum makine öğrenmesi kaba-kodu (pseudo-code) 
Kuantum makine öğrenimi işleminden sonra klasik makine öğrenimi adımına geçilmektedir. Bunun için kuantum makine öğrenmesinde kullanılan veriler, destek vektör makinesi algoritmasında da kullanılmıştır. Ayrıca çekirdek fonksiyonu lineer olarak ayarlanmıştır. Fonksiyonun python svm kütüphanesindeki svc modülünün varsayılan parametreleri kullanılmış olup herhangi bir optimizasyon işlemi yapılmamıştır. Yine aynı şekilde kuantum makine öğrenmesi algoritmasında kullanılan \%75 eğitim verileri, klasik algoritmanın eğitiminde kullanılmıştır. Daha öncesinde bu veriler normalizasyon işlemine uğradığı için bu işlem tekrar gerçekleştirilmemektedir. Sonrasında \%25'lik test verisi ile algoritmanın doğruluk oranı bulunmuştur.

DVM öğrenme modeli oluşturulmasının kaba-kodu Şekil 2.8'de gösterilmektedir. Burada DVM öğrenme modelinin adımları basit bir şekilde listelenmeye çalışılmıştır.

\section{Başlat}

2. Girdiler: $\quad X$ örnek özellik vektörlerinin listesi

Y çıktıların (etiketlerin) listesi

$\lambda$ düzenleştirme parametresi

T adımların sayısı

3. $w=(0, \ldots, 0)$

4. Döngü $\mathrm{t}=1$ 'den T'ye kadar

5. Seç eğitim örneği $x_{i}$ ve onunla ilişkili olan çıktı etiketi $y_{i}$

6. $\quad \eta=\frac{1}{\lambda . t}$

7. $\quad s k o r=w \cdot x_{i}$

8. $\quad$ Eğer y. skor $<1$ ise

9. $\quad w=(1-\eta \cdot \lambda) \cdot w+\left(\eta \cdot y_{i}\right) \cdot x_{i}$

10. Değilse

11. $\quad w=(1-\eta \cdot \lambda) \cdot w$

12. Çıktı $w$

\section{Bitir}

Şekil 2.8. DVM öğrenme modeli oluşturulması kaba-kodu (pseudo-code) (Shalev-Shwartz et al., 2011)

Burada, eta $(\eta)$, gradyan inişindeki adım uzunluğunu temsil etmektedir. Gradyan iniş algoritması, eğer adım uzunluğu $\eta$ uygun şekilde ayarlanmamışsa, minimumu bulmada bazı sorunlarla karşılaşıldığı belirtilmektedir. Bu sorunların önüne geçmek için değişken adım uzunluğu kullanılmaktadır (Johansson, 2015).

Öğrenme işlemleri tamamlanan kuantum ve klasik modele dışarıdan "Alışveriş Sayısı" ve "Yaş" değerine sahip bir örnek verilerek, ilgili bilgilere sahip kişinin ilgili ürünü alıp almayacağı tahmininin yapılması sağlanmıştır. 


\section{Bulgular ve Tartışma}

Çalışmadaki, kuantum makine öğrenimi ile klasik öğrenimi arasındaki farkı gözlemleyebilmek için bulut ortamından çekilen ve 211 örnekten oluşan, "Kullanıcıların Satın Alma Alışkanlığı” hakkında bilgilere sahip veri kümesinden yararlanılmıştır. Öğrenme modelini oluşturmak için yararlanılan veri kümesindeki "Alışveriş Sayısı" ve "Yaş" dağı̆lımı Şekil 3.1'de gösterilmiştir.

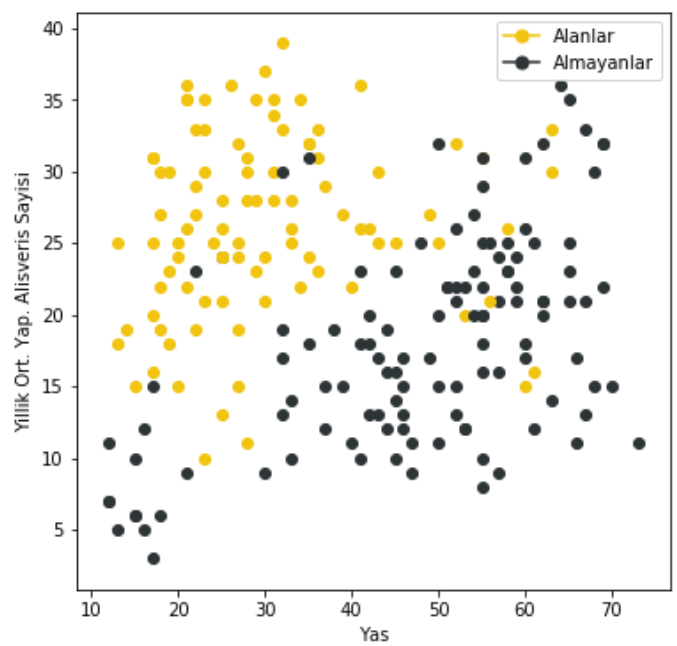

Şekil 3.1. Veri kümesindeki "Alışveriş Sayısı” ve "Yaş” dağılım grafiği

$\mathrm{Bu}$ veriler \%75 eğitim, \%25 test verisi olarak ayrılmıştır. Bu ayırma işleminden sonra gruplara atanan veri miktarları Çizelge 3.1'de verilmiştir.

Çizelge 3.1. Eğitim ve test için ayrılan örneklerin sayısı

\begin{tabular}{|c|c|c|}
\hline Toplam Örnek Sayısı & Eğitim Örneği Sayısı & Test Örneği Sayısı \\
\hline 211 & 158 & 53 \\
\hline
\end{tabular}

Kuantum makine öğrenmesi işleminde, öğrenme modelinin en uygun durumuna ulaşmasını sağlayacak algoritmanın 101 defa tekrarlanması sağlanmıştır.

Adım sayısı arttıkça öğrenme modelindeki kayıpların azaldığı Şekil 3.2.'de, bu doğrultuda da öğrenme uyarlamasının azaldığı Şekil 3.3.'de görülmektedir. Yapılan bu iterasyon sayesinde öğrenme modelinin hassaslığının arttığı gözlemlenmiş olup bu hassaslık sayesinde kritik konumlarda bulunan veri noktalarının doğru bir şekilde sınıflandırılması sağlanmıştır. 


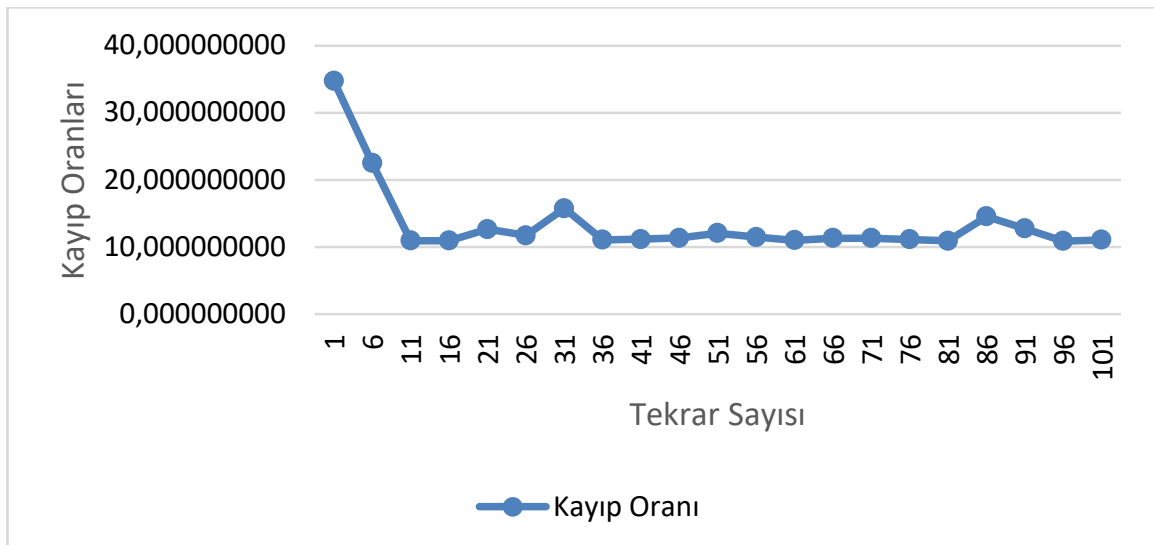

Şekil 3.2. Kuantum makine öğrenmesi algoritması kayıp oranları

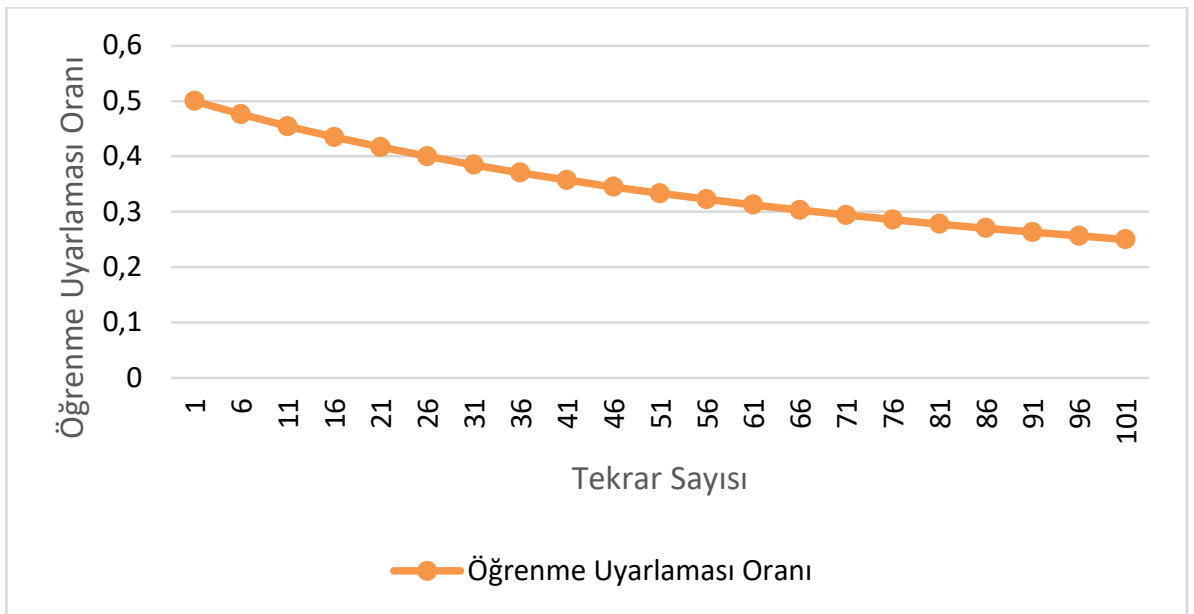

Şekil 3.3. Kuantum makine öğrenmesi algoritması öğrenme oranı uyarlaması (gradyan güncellemeleri)

Gerçekleştirilen kuantum makine öğrenmesi ve klasik makine öğrenmesi arasındaki doğruluk oranlarının karşılaştırması Çizelge 3.2.'de verilmiştir.

Çizelge 3.2. Kuantum ve klasik makine öğrenme algoritmalarındaki doğruluk oranları

\begin{tabular}{|l|c|c|}
\hline & Klasik & Kuantum \\
\hline Toplam Test Verisi Sayısı & 53 & 53 \\
\hline Doğru Tahmin Sayısı & 46 & 49 \\
\hline Yanlış Tahmin Sayısı & 7 & 4 \\
\hline Doğruluk Oranı (\%) & 86,8 & 92,5 \\
\hline
\end{tabular}

İlgili test verisinin, klasik ve kuantum makine öğrenme modeline uygulandıktan sonraki sonuçlar Çizelge 3.3. ve Çizelge 3.4.'de ifade edilen çapraz tahmin matrisi üzerinde gösterilmiştir. Çizelge 3.3.'deki klasik makine öğrenmesi sonuçlarına göre algoritma 17 pozitif tahmini (gerçekte ürün alınmış, tahminde alır olarak yapılmış) ve 29 negatif tahmini (gerçekte ürün alınmamış, tahminde almaz olarak yapılmış) doğru yapmıştır. Çizelge 3.4.'deki kuantum makine öğrenmesi sonuçlarına göre ise algoritma 21 pozitif tahmini ve 28 negatif tahmini doğru yapmıştır. 
Çizelge 3.3. Klasik makine öğrenimi çapraz tahmin (confusion) matrisi

\begin{tabular}{|c|c|c|c|}
\hline \multicolumn{4}{|c|}{ Klasik } \\
\hline & & \multicolumn{2}{|c|}{ Gerçek Değerler } \\
\hline & & Pozitif & Negatif \\
\hline \multirow{2}{*}{ 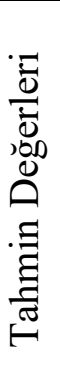 } & 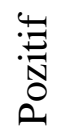 & 17 & 1 \\
\hline & 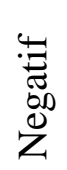 & 6 & 29 \\
\hline
\end{tabular}

Çizelge 3.4. Kuantum makine öğrenimi çapraz tahmin (confusion) matrisi

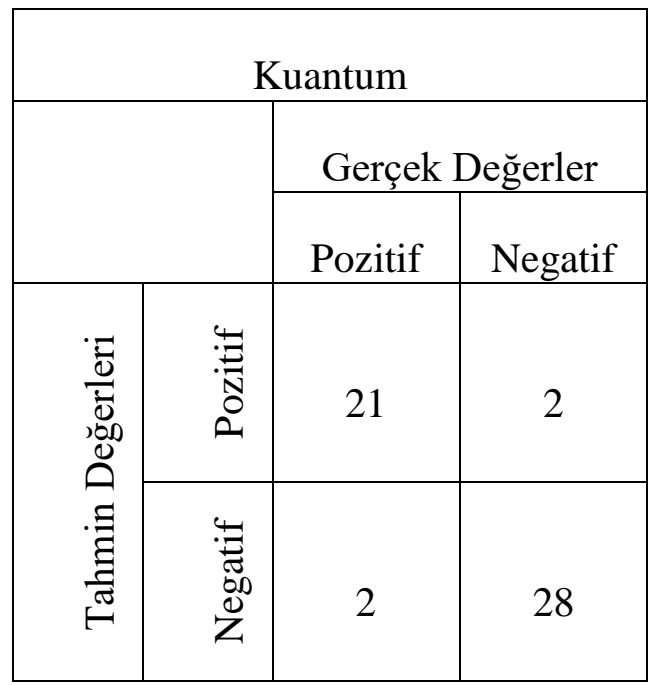

Çapraz tahmin matrislerinde gösterilen sonuçların oranları Çizelge 3.5.'da gösterilmiştir. $\mathrm{Bu}$ tablodaki oranlardan algoritmaların verimlilikleri hakkında sonuçlar elde edilmektedir.

Çizelge 3.5. Klasik ve kuantum makine öğrenme algoritmalarındaki çapraz tahmin (confusion) oranlar1

\begin{tabular}{|l|c|c|}
\hline & Klasik & Kuantum \\
\hline Doğruluk (Accuracy) & 0.87 & 0.92 \\
\hline Hata Oranı (Error Rate) & 0.13 & 0.08 \\
\hline Anma (Recall) (True Possitive Rate) & 0.74 & 0.91 \\
\hline Belirginlik (Specificity) (True Negative Rate) & 0.97 & 0.93 \\
\hline Yanlış Pozitif Oranı (False Possitive Rate) & 0.03 & 0.07 \\
\hline Kesinlik (Precision) & 0.94 & 0.91 \\
\hline
\end{tabular}

Alıcı İşletim Karakteristiği (AİK - ROC), bir olasılık eğrisini ifade etmektedir. Eğrinin Altındaki Alan (EAA - AUC) ise modelin, tahmin gücünü diğer bir deyişle sınıflar arasındaki ayrım kapasitesini ifade etmektedir. AUC yükseldikçe, yani 1'e yaklaştıkça modelin tahmin gücü yükselmektedir. Şekil 3.4.'de görüldüğü üzere kuantum makine öğrenmesine ait AUC değeri 0.923, klasik makine öğrenmesine ait AUC değeri ise 0.853 olarak tespit edilmiştir. $\mathrm{Bu}$ değerlerden yola çıkarak kuantum makine öğrenmesinde elde edilen modelin daha iyi tahminler yaptığı sonucuna ulaşılmıştır. 

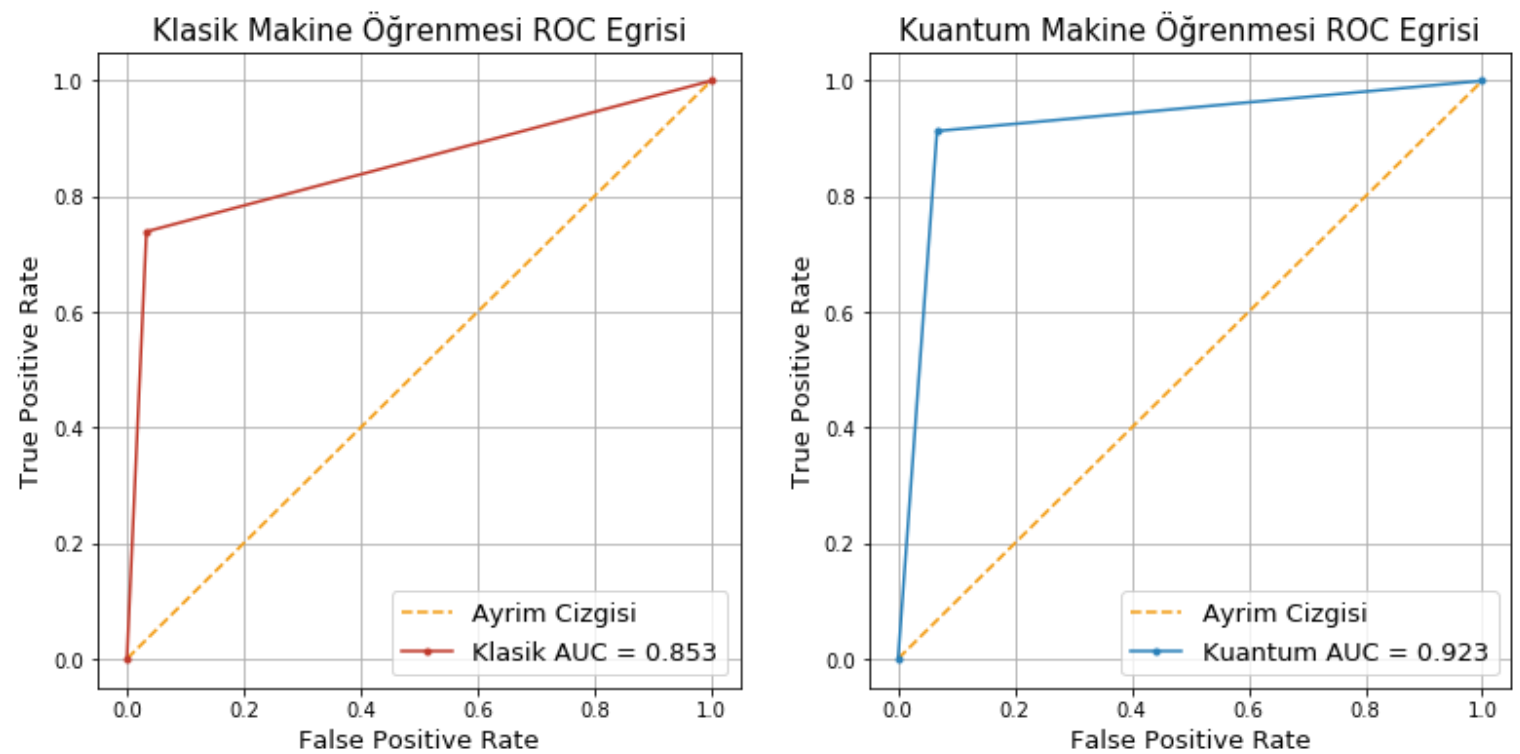

Şekil 3.4. Klasik ve kuantum makine öğrenmelerine ait ROC eğrileri

İlgili öğrenme işlemlerinden sonra örnek kullanıcı bilgileri girilerek her iki algoritmanın da bu bilgilere göre sınıflandırma işlemi yapması sağlanmıştır. İlgili girdiler Şekil 3.5'de gösterilmektedir.

Birinci örnek denemesi:

Yasi Giriniz : 35

Yillik Ort. Yap. Alisveris Sayisi : 30

Yeni girdilerin normalize edilmis hali : [[0.40350877 0.73529412]]

Şekil 3.5. Birinci örnek girdi değerleri

Girilen değerlerin, hangi konuma denk geldiği Şekil 3.6'da gösterilmektedir. Görüldüğü üzere bulunulan konum, ürünü alanların çoğunlukta olduğu kısıma denk gelmektedir. Şekil 3.7 ise bu sonucun metinsel olarak çıktısını göstermektedir.

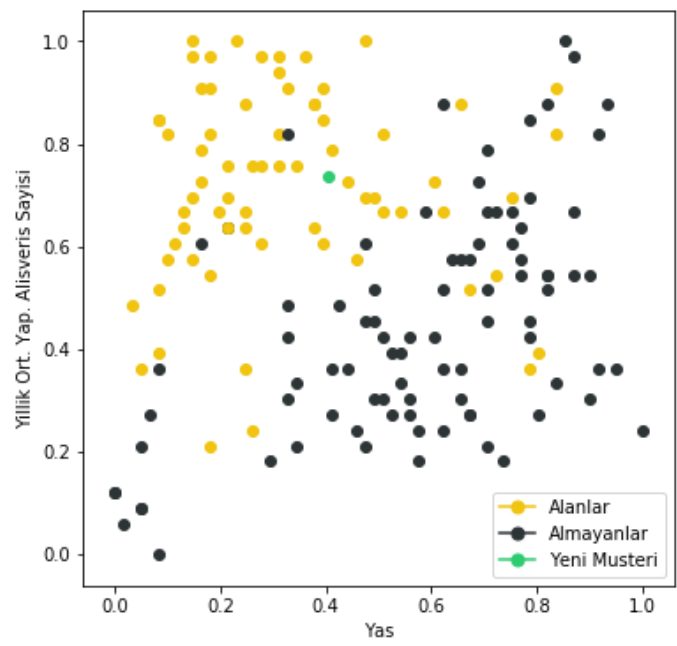

Şekil 3.6. Birinci örnek girdisinin, diğer veriler içerisindeki konumu 
86.8 dogruluk oranina sahip Klasik ML e gore musteri; Urunu alabilir.

92.5 dogruluk oranina sahip Kuantum ML e gore musteri; Urunu alabilir.

Şekil 3.7. Birinci örnek girdisinin sınıflandırma sonuçları

İkinci örnek denemesine ait girdiler Şekil 3.8'de gösterilmektedir.

Yasi Giriniz : 47

Yillik Ort. Yap. Alisveris Sayisi : 15

Yeni girdilerin normalize edilmis hali : [[0.61403509 0.29411765]]

Şekil 3.8. İkinci örnek girdi değerleri

Girilen değerlerin hangi konuma denk geldiği Şekil 3.9'da gösterilmektedir. Görüldüğü üzere bulunulan konum ürünü almayanların çoğunlukta olduğu kısıma denk gelmektedir. Şekil 3.10 ise bu sonucun metinsel olarak çıktısını göstermektedir.

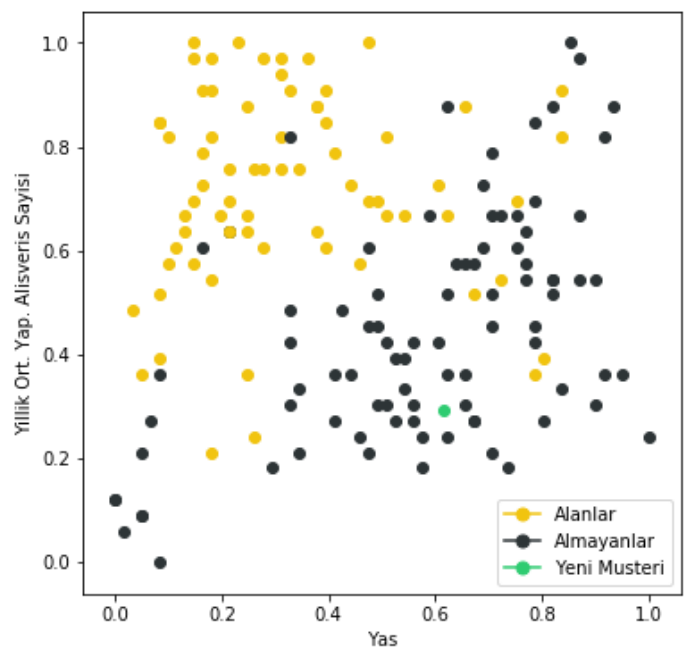

Şekil 3.4. İkinci örnek girdisinin, diğer veriler içerisindeki konumu

86.8 dogruluk oranina sahip Klasik ML e gore musteri; Urunu almayabilir.

92.5 dogruluk oranina sahip Kuantum ML e gore musteri; Urunu almayabilir.

Şekil 3.10. İkinci örnek girdisinin sınıflandırma sonuçları

\section{Sonuç}

Kuantum bilgisayarlar ve makine öğrenmesi çalışmaları ayrı ayrı olarak yıllar öncesine dayanmaktadır. $\mathrm{Bu}$ iki alanı birbirine yaklaştıran şey teknolojinin gelişmesiyle birlikte işlenmesi gereken veri miktarlarının çok büyük boyutlara ulaşması ve artık klasik yöntemlerin yetersiz kalması olarak görülmektedir. Son yıllarda ise klasik yöntemlerdeki bu yetersizliğinin kuantum yöntemlerinin üstün özelliklerini kullanarak üstesinden gelinebileceği düşünülmektedir.

Bilindiği üzere kuantumsal sistemlerin davranışlarında süreklik mevcuttur. Işık buna prototip bir örnek olarak gösterilebilir. Bu anlamda bilim insanları, kuantum davranışları direkt olarak anlamak adına çalışmalar yapmaktadırlar ve kuantum sistemlerin davranışlarındaki dalgaları 
algılayan dedektörler geliştirerek kuantum bilgisayarları inşa etmeye çalışmaktadırlar. Bu tarz sistemler genel olarak sürekli-değişken model olarak anılmaktadır. Sürekli-değişken model, günüüzde kuantum teknolojilerinin daha ileri safhasında olacağı yapıyı temsil etmektedir. $\mathrm{Bu}$ çalışmada kuantum sürekli-değişken modeli üzerinde yapılan makine öğrenmesi incelenmiştir.

İki boyutlu verilerde desen tanıma görevi için kuantum varyasyonel devre üzerinde öğrenme işlemi simülasyon ortamında gerçekleştirilmiştir. Öğrenme işlemi sonucunda kuantumsal işlemler ve uygulanan iterasyon sonucunda muadili olan klasik makine öğrenmesi algoritmasından daha hassas olarak sınıflandırma yaptığı tespit edilmiştir. Sürekli-değişken model kuantum sistemlerin yaygınlaşmasıyla bu işlemlerin kuantumsal sistemler üzerinde daha hızlı ve kısa sürede gerçekleştirilebileceği öngörülmektedir. Kuantum makine öğrenmesinin üstünlüğü doğrultusunda; bu çalışmada elde edilen sonuçlar Grant ve ark. (2018) tarafından elde edilen sonuçlar ile uyum içindedir.

\section{Teşekkür}

Bu çalışma Ömer ERYILMAZ’ın “Kuantum Temelli Gözetimli Bazı Makine Öğrenme Algoritmalarının Gerçekleştirimi ” başlıklı Yüksek Lisans Tezi kapsamında üretilmiştir. 


\section{Kaynakça}

Braunstein S. L., Loock P., 2005. Quantum Information With Continuous Variables. Reviews Of Modern Physics, 77:p513.

Eryılmaz Ö., Y1lmaz İ., (1 Mart 2019). Github. QML Sample Source Code. 2019. https://github.com/omereryilmaz/master-thesis-qml.

Grant E., Benedetti M., Cao S., Hallam A., Lockhart J., Stojevic V., Green A., Severini S., 2018. Hierarchical Quantum Classifiers. Quantum Information (2018) 4:65 https://doi.org/10.1038/s41534-018-0116-9.

Izaac J., (25 Aralık 2018). Numerical Learning: Supervised Learning. 3 Temmuz 2018a https://qmlt.readthedocs.io/en/latest/tutorials/numerical.html\#supervised-learning.

Izaac J., (25 Aralık 2018). Continuous-Variable Quantum Computing: Conventions And Formulas. 3 Temmuz 2018b. https://strawberryfields.readthedocs.io/en/latest/conventions/gates.html.

Johansson R., (20 Aralık 2018). Clarification Of The Pseudocode In The Pegasos Paper. 2015. https://svn.spraakdata.gu.se/repos/richard/pub/ml2015_web/a2_clarification.pdf.

Jordan S.,(20 Aralık 2018). Quantum Algorithm Zoo: Algebraic And Number Theoretic Algorithms. 13 Haziran 2018. http://math.nist.gov/quantum/zoo/.

Killoran N., Izaac J., Quesada N., Bergholm V., Amy M., Weedbrook C., 2018. Strawberry Fields: A Software Platform for Photonic Quantum Computing. arXiv:1804.03159v1. Xanadu, 372 Richmond St W, Toronto, M5V 1X6, Canada.

Nielsen M. A., Chuang I., 2002. Quantum Computation And Quantum Information. Cambridge University Press, Cambridge, UK. 40-58.

Schuld M., Sinayskiy I., Petruccione F., 2014. An Introduction To Quantum Machine Learning. Contemporary Physics 56(2). arXiv:1409.3097. 1-3.

Schuld M., (27 Aralık 2018). Quantum Machine Learning Toolbox: Variational Circuits. 3 Temmuz 2018. https://qmlt.readthedocs.io/en/latest/variational.html\#variational.

Schuld M., Bocharov A., Svore K., Wiebe N., 2018. Circuit-Centric Quantum Classifiers. arXiv:1804.00633v1. 1-2. 
Shalev-Shwartz S., Singer Y., Srebro N., Cotter A., 2011. Pegasos: Primal Estimated SubGradient Solver For SVM. Mathematical Programming Volume 127: 3-30. 